\title{
Assessing Knowledge on Clubfoot Among Parents Having Children with Clubfoot Deformity
}

\author{
Zobaer Alam ${ }^{1}$ \\ Md Monoarul Haque ${ }^{2 *}$ \\ Md Rijwan Bhuiyan ${ }^{3}$ \\ Md Shahinoor Islam² \\ Monirul Haque ${ }^{4}$ \\ A S M Mazharul Islam ${ }^{5}$ \\ Md Shafiullah Pradhania ${ }^{6}$
}

${ }^{1}$ Centre for Injury Prevention and Research Bangladesh.

${ }^{2}$ Department of Community Nutrition Faculty of Public Health

Bangladesh University of Health Sciences (BUHS) Dhaka, Bangladesh

${ }^{3}$ Department of Health Education \& Health Promotion Bangladesh Institute of Health Sciences, Dhaka, Bangladesh

${ }^{4}$ Department of Physiotherapy

Panaroma General Hospital, Dhaka, Bangladesh.

${ }^{5}$ Department of Physiotherapy

Ibrahim General Hospital, Dhaka, Bangladesh.

${ }^{6}$ DPRC Hospital \& Research Center

Adabor, Dhaka, Bangladesh.

\section{*Correspondence to:}

\section{Md Monoarul Haque}

Fellow

Department of Community Nutrition

Faculty of Public Health

Bangladesh University of Health Sciences (BUHS)

125/1, Darus Salam, Mirpur, Dhaka-1216, Bangladesh.

Mobile : +8801915839550;

E-mail:monoarmunna@yahoo.com

http://www.banglajol.info/index.php/CMOSHMCJ

\begin{abstract}
Background: The burden of childhood disability as a public health problem in developing countries remains relatively unrecognized. One out of 750 children born in the world suffer from club foot among them $80 \%$ are in low and middle income countries. Most of these babies have limited access to receive effective treatment for their clubfoot due to lack o knowledge, awareness and some barriers. We actually don't know the level of knowledge of parents who have child with clubfoot deformity. The purpose of this study was to assess the level of knowledge of parents who have children with clubfoot during clubfoot treatment. Materials and Methods: This cross sectional study was conducted among 102 parents who have children with clubfoot deformity during its treatment in a selected clinic. The samples were selected purposively from the clinics where clubfoot treatment was given and face to face interview was done by using semi-structured questionnaire. Results: The mean $( \pm \mathrm{SD})$ age of the respondents were $24.7( \pm 6.0)$ years where $87.3 \%(\mathrm{n}=89)$ respondents ware female and $59.8 \%(\mathrm{n}=61)$ respondent's educational status ware up to primary level. About $44.1 \%$ respondents started treatment of their child within 6 months of birth and 33\% within 6 to 12 months where $57 \%$ ( $n=58)$ respondents are referred by health care professional to this clinics. About $93.1 \%$ of parents $(n=95)$ said that they knew nothing about clubfoot deformity before their child was diagnosed where $97 \%$ are aware after diagnosis of their child. About 93.1\% respondents knew the best time for treatment initiation where 59.8\% respondents know the correct follow up time of clubfoot management. In case of knowledge of parents' roles in the treatment of clubfoot about $91.2 \%$, parents have knowledge weekly visit for treatment and $86.3 \%$ know the plaster care where $52.9 \%$ $(n=54)$ parents have lack of knowledge about how to use the brace Conclusion: There is need to improve the communication skills of clinicians/health care providers offering treatment to children with clubfoot at the Clinics. Need to share information with the parents about the condition. Finally, there is need to emphasize of educating parents about plaster care and how to use brace.
\end{abstract}

Key word: Club foot; Deformity; Plaster; Brace.

\section{INTRODUCTION}

The burden of childhood disability as a public health problem in developing countries remains relatively unrecognized ${ }^{1}$. One out of 750 children born in the world suffer from club foot. Around 220000 babies in developing countries born with clubfoot each year ${ }^{2}$. Study shows approximately $80 \%$ of total clubfoot is in low and middle income countries ${ }^{2,3}$. Most of these babies have limited access to receive effective treatment for their clubfoot and will grow up with severe disability as a consequence ${ }^{3}$. In America and the United Kingdom the estimate incidence of clubfoot is 1 per 1000 births, with males more affected than females in a ratio of $2: 1^{4}$. However another findings indicate an incidence of 2 to 3 per 1000 births in developed countries ${ }^{5}$. Additionally the incidence of clubfoot among black South African children is reported to be $3.5 / 1000$ births $^{6}$. 
Although it is estimated that $80 \%$ of the world's disabled children live in developing countries, not much is known about the disabling conditions such as clubfoot in these countries ${ }^{7}$. In Bangladesh the estimated number of children with clubfoot born per year is about 4373, and an incidence rate of club foot is $1.2 / 1000$ births $^{8}$. Every year in Bangladesh and Myanmar an estimated 5-6000 children are born with clubfoot deformity every year, which is approximately one of every 1000 children born in our country ${ }^{9}$. Untreated or incorrectly treated clubfoot soon becomes 'neglected clubfoot' as the child grows. A child with neglected clubfoot will have difficulty in wearing normal shoes and as they grow older may experience severe pain. Neglected clubfoot severely restricts ability to walk in some cases, and in others only short distances are manageable. The burden of this disability impacts on society as a whole and as such the problem of untreated clubfoot should be viewed as a public health issue which must be addressed ${ }^{3}$. Due to lack of knowledge, awareness and poor access to healthcare most children with clubfoot in developing countries have limited access to receive treatment. Left untreated, clubfoot results in severe disability, causing pain and difficulty in walking. Many individuals with untreated clubfoot end up living as beggars on the streets ${ }^{10}$. It has been shown that only $10 \%$ of children with clubfoot in East Africa are able to access treatment from a specialist owing to inadequate awareness, poor communication, travel expenses and increased parental responsibilities of care in the family ${ }^{11}$. Currently, only $2 \%$ out of over one million people with disabilities in Uganda receive rehabilitation services ${ }^{12}$. Patient compliance with treatment procedures is important for the therapeutic regimen to be effective. Without compliance, the therapeutic goals cannot be achieved, resulting in poor patient outcomes ${ }^{13}$. Research on adherence to pediatric treatment regimes has received attention in recent years as sub optimal adherence to medical and other therapeutic regimens can have personal, social and clinical implications for the child as an adult ${ }^{14}$. Lack of information regarding reasons for adherence to the regimen makes it difficult for health providers and health planners to determine the impact of treatments on health status or weigh the cost/benefit ratio for prescribing costly treatments to the patients ${ }^{15}$. Therefore, it is important to understand how parents/caregivers manage their children's treatment and the potential barriers these parents encounter during the utilization of clubfoot treatment services. Despite serious consequences of poor compliance to prescribed therapeutic regimens for children with physical and mental impairments, compliance or treatment adherence in this group of children has not been well studied ${ }^{16}$. Studies in developing countries with low-resource settings have shown that multiple barriers affect patient or caregiver's utilization of health care services. In a study in Ghana, found that level of awareness along with distance travelled to health facilities, cost of treatment, long waiting times and negative attitudes of health care providers were major barriers to utilization of health care services ${ }^{17,18}$. Additionally good communication and information sharing between the patients and the health provider during clinical encounters and consultations is important for mutual understanding and agreement and is a good predictor of compliance to the prescribed care ${ }^{19,20,21}$. In this study we tried to find out the knowledge level of parents about clubfoot and its management and as well as their future role during clubfoot treatment in clinic of their children with clubfoot deformity. We will assess the knowledge level about Clubfoot deformity before and after diagnosis, knowledge about club foot management and follow up system and their current and future role in the treatment of clubfoot.

\section{MATERIALS AND METHODS}

\section{Study design}

This cross sectional study was conducted among the parents who have children with clubfoot deformity during its treatment in selected clinics.

\section{Study area and population}

The population of this study was the parents who have children with congenital clubfoot deformity attending in the selected clinic for treatment. Both male and female parents were recruited for interview. The study was conducted in Bangladesh, at the 'Nilphamari' and 'Rangpur' general disability clinics (conducted by 'The Leprosy Mission International, Bangladesh') and in 'National Institute of Traumatology and Orthopedics Rehabilitation (NITOR)'.

\section{Study sample and sampling method}

To conduct study 102 samples were selected purposively from the selected clinics from January 2011 to June 2011. The parents who have children with clubfoot age up to 2 years, who are currently receiving treatment and undergoing plaster casting are the samples of this study. Children who have clubfoot with other additional disabilities and other relatives who were not principle caregivers of children with clubfoot are excluded from this study sample.

\section{Data collection tools and techniques}

Data were collected by face to face interview. On average, 2530 minutes were spent for each of the patients. A pre-tested semi-structured questionnaire in 'Bangla' was used for data collection. The questionnaire was pre-tested with similar type of patients who were not included in the study sample. Some modifications and corrections were done subsequently using the feedback from pre-testing.

\section{Data analysis}

After collection data were checked thoroughly for consistency and completeness. Data were cleaned, edited and verified on daily basis to avoid any error or inconsistency. Incomplete or erroneous data were discarded. SPSS (Statistical Package for Social Sciences) Statistics version 16 was used to analyze the data. After the entry, range, consistency and normal distributions were checked. Descriptive statistics were computed for all categorical variables.

\section{Ethical issues}

Purpose of data collection was explained to the respondents and informed written consents were taken from the respondents prior to data collection. Respondents' dignity and respects were maintained and interviews were taken with strict privacy. The respondents were informed clearly that their personal identity would be kept confidential and the data would be used only for study purpose. Moreover, participants were allowed to withdraw themselves at any stage of the study. Neither any drug nor any invasive procedure was applied. 


\section{RESULTS}

Socio-demographic characteristics of the respondents

Of 102 respondents, the age ranges were from 14 years to 40 years. The mean \pm SD age was $24.7 \pm 6.0$ years. About $58.8 \%$ (60) respondents were in younger age group (20-30 years). Rest of $28.5 \%$ (29) was in age group 14 to 20 years and $12.7 \%$ (13) are in age group 31 to 40 years. The results shows $87.3 \%$ (89) respondents ware female and $12.7 \%$ (13) ware male. In case of occupation, study shows that about $51 \%$ (52) ware house wife and rest of them ware service holder $17.6 \%$ (18), business man $13.7 \%$ (14), day labor $11.8 \%$ (12), farmer $4.9 \%$ ( 5) and only one percent was unemployed. About $59.8 \%$ (61) respondent's educational status ware up to primary level where $28.4 \%$ (29) had no formal education. Only 7.8\% (8) parents had University level education. Rest of $21.6 \%$ (22) of parents had secondary level education and $10.8 \%$ (11) had higher secondary school level education. Results show about $44.1 \%$ respondents started treatment of their child within 6 months of birth and 33\% within 6 to 12 months. In case of referral to the clinic, about Fifty-seven percent of the children $(n=58)$ were referred by friends or neighbor, $38.2 \%$ of children $(n=39)$ were referred by medical professionals, $2 \%$ of children $(n=2)$ were referred by traditional birth attendants, parents of $2.9 \%$ of children $(n=3)$ referred themselves to the clinic (Table-1).

Table 1 : Socio-demographic characteristics of respondents

\begin{tabular}{|c|c|c|c|}
\hline $\begin{array}{l}\text { Items } \\
\text { Age (years) }\end{array}$ & Frequency & Percentage & Mean \pm SD \\
\hline Up to $20 \mathrm{yrs}$ & 29 & 28.5 & \\
\hline $21-30 \mathrm{yrs}$ & 60 & 58.8 & $24.7 \pm 6$ \\
\hline $31-40$ yrs & 13 & 12.7 & \\
\hline Total: & 102 & 100 & \\
\hline \multicolumn{4}{|l|}{ Gender } \\
\hline Male & 13 & 12.7 & \\
\hline Female & 89 & 87.3 & \\
\hline Total & 102 & 100 & \\
\hline \multicolumn{4}{|l|}{ Occupation } \\
\hline Service & 18 & 17.6 & \\
\hline Business & 14 & 13.7 & \\
\hline Unemployed & 1 & 1.0 & \\
\hline House wife & 52 & 51.0 & \\
\hline Farmer & 5 & 4.9 & \\
\hline Day labor & 12 & 11.8 & \\
\hline Total & 102 & 100 & \\
\hline \multicolumn{4}{|c|}{ Educational Status } \\
\hline \multicolumn{2}{|c|}{ No formal education 29} & 28.4 & \\
\hline \multicolumn{4}{|c|}{ Secondary School } \\
\hline Certificate & 22 & 21.6 & \\
\hline \multicolumn{4}{|c|}{ Higher Secondary } \\
\hline Certificate & 11 & 20.8 & \\
\hline Graduate level & 8 & 7.8 & \\
\hline Total & 102 & 100 & \\
\hline
\end{tabular}

$\begin{array}{llll}\text { Items } & \text { Frequency } & \text { Percentage } & \\ \text { Age (years) } & & & \text { Mean } \pm \text { SD }\end{array}$

Age of treatment commencement

$\begin{array}{lll}0 \text { to }<6 \text { months } & 45 & 44.1 \\ 6 \text { to }<12 \text { months } & 34 & 33 \\ 12 \text { to } 24 \text { months } & 23 & 22.9 \\ \text { Total } & \mathbf{1 0 2} & \mathbf{1 0 0}\end{array}$

Referred to the clinic

Friends/Neighbor $58 \quad 57$

Medical professional $39 \quad 38.2$

$\begin{array}{lll}\text { TBA } & 2 & 2\end{array}$

$\begin{array}{lll}\text { Self } & 3 & 2.9\end{array}$

Total $102 \quad 100$

Knowledge about Clubfoot deformity

Parents were asked their knowledge about clubfoot before and after diagnosis and their view on the importance of treatment after diagnosis. From the total sample, $93.1 \%$ of parents $(n=95)$ indicated that they knew nothing about clubfoot deformity before their child was diagnosed. $6.9 \%$ of parents $(n=7)$ indicated that they knew about clubfoot deformity before their child was diagnosed. Within $6.9 \%(n=7)$ who knew before diagnosis, four of them was informed by doctors or health worker and three from friends or neighbors. On the other hand, $92.2 \%$ of parents $(n=94)$ indicated that this disease is curable and rest of $7.8 \%$ parents believe that it is not a curable disease. After diagnosis of their child about $97 \%(n=99)$ respondents have basic knowledge about clubfoot where 3\% $(n=3)$ are not clear about clubfoot (Table 2).

Table 2 : Knowledge level about Clubfoot deformity, management and follow up

Knowledge Frequency Percent

Knowledge on Clubfoot before Diagnosis

$\begin{array}{lcc}\text { Yes } & 7 & 6.9 \\ \text { No } & 95 & 93.1 \\ \text { Total } & \mathbf{1 0 2} & \mathbf{1 0 0} \\ \text { Knowledge on Clubfoot after Diagnosis } & \\ \text { Yes } & 99 & 97 \\ \text { Not much clear } & 3 & 3 \\ \text { Total } & \mathbf{1 0 2} & \mathbf{1 0 0} \\ \text { Is it curable } & & \\ \text { Yes } & 94 & 92.2 \\ \text { No } & 8 & 7.8 \\ \text { Total } & \mathbf{1 0 2} & \mathbf{1 0 0}\end{array}$

Knowledge about Best treatment time and duration of treatment

$\begin{array}{lcc}\text { Yes } & 95 & 93.1 \\ \text { No } & 7 & 6.9 \\ \text { Total } & 102 & 100 \\ \text { Knowledge about follow up time } & \\ >\text { 2 years } & 31 & 30.4 \\ <2 \text { years } & 61 & 59.8 \\ \text { Not sure } & 10 & 9.8 \\ \text { Total } & \mathbf{1 0 2} & \mathbf{1 0 0}\end{array}$




\section{Knowledge about club foot management and follow up}

About $11.8 \%$ respondent did not know what is the best time for treatment and total treatment time for clubfoot management. More than two-third of respondents said that the best time for treatment is as soon as birth and total treatment time is more than six months. And $59.8 \%$ respondents $(n=61)$ thinking that the follow up time of clubfoot management is more than 2 years where $30.4 \%(n=31)$ thinking that follow up will be less than 2 years. On the other hand $9.8 \%$ respondents $(n=10)$ do not know what is the follow up time for clubfoot management (Table 2).

\section{Knowledge of parents of their current role in the treatment of clubfoot}

In case of knowledge of parents' current roles in the treatment of clubfoot included: bringing the child every week for treatment; and taking care of plaster casts which involved preventing plasters from being soaked with water, preventing the urine going into the plaster cast, and preventing the child playing on wet floor or ground. About $91.2 \%$, parents have knowledge that it was their prime responsibility to bring the child every week for treatment and $86.3 \%$ know the plaster care where $2 \%$ and $5.9 \%$ don't know the visit time, plaster care respectively (Table 3 ). The child is required to wear these braces for 23 out of 24 hours every day for three months, and for two years at night and nap times only. From the total sample, $39.2 \%$ percent of parents $(n=40)$ indicated that they did not know that it was their responsibility to ensure that the child would wear abduction braces after the plaster-casting phase where $52.9 \%(\mathrm{n}=54)$ parents know how to use the brace (Table 3$)$.

Table 3 : Parents' future role on clubfoot management $(n=102)$

\begin{tabular}{lcccccc} 
& \multicolumn{2}{c}{$\begin{array}{c}\text { Regularly visit clinic } \\
\text { Frequency }\end{array}$} & $\begin{array}{c}\text { Percent } \\
\text { Frequency }\end{array}$ & $\begin{array}{c}\text { Percent } \\
\text { Frequency }\end{array}$ & $\begin{array}{c}\text { Percent } \\
\text { Fre brace accordingly }\end{array}$ \\
Yes & 93 & 91.2 & 88 & 86.3 & 54 & 52.9 \\
No & 00 & 00 & 1 & 1.1 & 1 & 1 \\
Do not know & 2 & 2 & 6 & 5.9 & 40 & 39.2 \\
Total & 95 & & 95 & & 95 &
\end{tabular}

In case of plaster care, about $91.2 \%$ respondents know to preventing child with plaster cast from playing on wet floor or ground. About $77.5 \%(\mathrm{n}=79)$ parents knew preventing the urine going into the plaster cast and $51 \%(\mathrm{n}=52)$ knew to prevent their child playing with plaster where $2 \%, 14.7 \%$ and $45.3 \%$ parents report that they don't know well about protecting plaster from water, preventing urine going into the plaster and preventing their child playing with plaster respectively (Table 4).

Table 4 : Parents' future role on plaster management $(n=102)$

\begin{tabular}{lcccccc} 
& \multicolumn{2}{c}{ Don't wet in water } & \multicolumn{2}{c}{ Urine in plaster } & \multicolumn{2}{c}{ Play with plaster } \\
& Frequency & Percent & Frequency & Percent & Frequency & Percent \\
Yes & 93 & 91.2 & 79 & 77.5 & 52 & 51 \\
No & 00 & 00 & 00 & 00. & 43 & 00 \\
Do not know & 2 & 2 & 15 & 14.7 & 43 & 45.3 \\
Total & 95 & & 94 & & 95 & \\
\hline
\end{tabular}

\section{DISCUSSION}

Public health planners have recognized the importance of health workers being informed about the knowledge and perceptions which people hold regarding health and illness, causes of disease and possible remedies ${ }^{22}$. Theorists have proposed that a mismatch between the patient/caregivers' and the therapist's expectations for treatment may lead to dissatisfaction with services and may lead to poor adherence to the treatment regime ${ }^{23}$. For instance if patients/caregivers have little knowledge about the condition and are unfamiliar with the process of treatment, they may have unrealistic expectations about how long the treatment will last, how quickly their child's problem will resolve, and to what extent they will be expected to participate in treatment ${ }^{23}$. In this study, shows almost majority of the respondents did not aware of clubfoot deformity before diagnosis of their children where almost 97\% $(n=99)$ are aware and know about clubfoot deformity after diagnosis of their children. Almost majority respondents answered that they know clubfoot is curable if proper management is taken timely where $95 \%$ answered correctly, when treatment should be started and duration of treatment. In case of follow up, more than half of the respondents answered 2 years or more where one third said that the follow up is less than 2 years and minority $(10 \%)$ are not sure about the follow up system. However, despite the inadequate knowledge (93.1\%) prior to diagnosis, $97 \%$ of parents $(n=99)$ indicated they understood the clubfoot and its treatment regimen. This indicates that these parents learnt about some aspects about clubfoot and its treatment including the benefits of adhering to the prescribed treatment during the time they attended for the treatment of their children. However it is not known whether this parental learning was through exposure to the treatment or was obtained from fellow parents that had started bringing their children earlier for treatment or those that had undergone several treatment sessions at the clinic. Study also shows that majority of the respondents know the regular visiting time $(91.2 \%)$, Plaster care $(86 \%)$ where half of the respondents knew how to use brace correctly. In case of plaster care, majority respondents aware about not to wet plaster in water and more than two third are aware about preventing urine of their children go into the plaster where half of the respondents are aware not to allow their child to play wearing plaster. The results of this study are consistent with the findings in Manchester, United Kingdom, on caregiver's knowledge of dysphasia and its influence on adherence to dysphasia management strategies ${ }^{24,25}$. They found that while only $45 \%$ of caregivers $(n=46)$ had good knowledge about dysphasia, $77 \%$ of these caregivers adhered to the required management strategies of dysphasia. The results of the current study indicate that parents had poor knowledge about clubfoot and its treatment initially but acquired more through successive attendance to the treatment for their children. But study found that about half of the respondents have lack of knowledge on using brace and playing with plaster.

\section{CONCLUSION}

The study identified the after diagnosis and starting management the parents are aware about their child's problems. On the other hand some respondents have lack of knowledge about the use of brace and care of plaster. This should be focused by the health care providers to the parents. This study provides information on the factors that might improve in order to improve the adherence of parents to their children's treatment in the clinic.

\section{DISCLOSURE}

All the authors declared no competing interest. 


\section{REFERENCES}

1. Shawky S, Abalkhail B and Soliman N An epidemiological study of childhood disability in Jeddah and Saudi Arabia, Paediatric and Perinatal epidemiology. 2002; 16(1): 61-66.

2. Cure club foot (2013), Available on [Online] http://cure.org/clubfoot (accessed 2 Jun 2013).

3. Global Clubfoot Initiative (2010), Clubfoot in Low and Middle Income Countries (LMIC), Available on [Online] http://globalclubfoot.org/clubfoot/low-middle-income-countries/ (accessed 5 June 2013).

4. Moorth RN, Hashmi SS, Langois P, Canfield M, Waller DK and Hecht JT Idiopathic talipes equinovarus (ITEV) (clubfoot) Texas. American Journal of Medical Genetics. 2005; 132(4): 376-380.

5. Pandey S and Pandey AK The classification of clubfoot, a practical approach. The Foot. 2003; 13(2): 61-65

6. Ballantyne JA and Macnicol MF Congenital talipes equinovarus (clubfoot): an overview of the aetiology and treatment. Minisymposium: The paediatric foot. Current Orthopaedics. 2002; 16: 85-95.

7. Shawky S, Abalkhail B and Soliman N An epidemiological study of childhood disability in Jeddah. Saudi Arabia. Paediatric and Perinatal epidemiology. 2002; 16(1): 61-66.

8. Global Clubfoot Initiative: Bangladesh Profile (2010) UK, Available on [Online] http://globalclubfoot.org/countries/bangladesh/ (accessed 10 Aug 2013).

9. Walk for life: Bangladesh office (2012) Bangladesh Clubfoot program. Available on [Online] http://www.walkforlife.org.au/ (accessed 10 May 2013).

10. Harrison R, Penny R, Mayo A, Morcuende J and Lavy C (2010) Global Clubfoot Project 2007-2009: Summary of Outcomes, Institute of Child Healt London.Availableon[Online]http://www.cbm.org/article/downloads/72942/Global_Clubfoot_Project_poster.pdf (accessed 10 May 2013).

11. Scott R and Evans S Non-specialist management of tropical talipes. Tropical Doctor. 1997; 27 (1): 22-25.

12. $\mathrm{MOH}$ (2003) Essential services for rehabilitation health care for persons with disabilities in the district. Available on [Online] www.health.go.ug/docs/Rehab.pdf [accessed 10 May 2013].

13. Cameroon C Patient compliance: Recognition of factors involved and suggestions for promoting compliance with therapeutic regimens. Journal of Advanced Nursing. 1996;24(2): 244-250.

14. De Civita M and Dobkins PL Paediatric adherence: conceptual and methodological considerations. Children's Health Care. 2005; 34(1): 19-34.

15. Modi AC, Lim CS, Yu N, Geller D, Wagner MH and Quittner AL A multi-method assessment of treatment adherence for children with cystic fibrosis. European Child and Adolescent Psychiatry. 2006;15(5): 265-276.

16. Barakat LP, Whitley .S and Kwaku OF Treatment of adherence in children with sickle cell disease: Disease-related risk and psychosocial resistance factors. Journal of Clinical Psychology in Medicine settings. 2002; 9 (3): 201-209.

17. Tolhurst R and Nyonator FK Looking within the household: gender roles and responses to Malaria in Ghana. Transactions of the Royal Society of Tropical Medicine and Hygiene. 2006;100 (4): 321-326.

18. Olova MS, Munoz B, Lynch M, Mkocha H, and West SK Evaluation of barriers to surgical compliance in the treatment of trichiasis. International Ophthalmology. 21(4): 235-241.

19. Izugbara CO, Etukudoh, IW and Brown AS Transethnic itineraries for ethnomedical therapies in Nigeria: Igbo women seeking Ibibio cures. Health and Place. 2005; 11(1): 1-14

20. Ambruoso L, Abbey M and Hussein J Please understand why 1 cry out in pain: women's accounts of maternity services during labour and delivery in Ghana. BMC. 2006; 5 (2): 140

21. Wieringen JC, Harmsen JAM and Bruijnzeels MA Intercultural communication in general practice. The European Journal of Public Health. 2002; 12(1): 63-68.

22. Dyer SJ, Abraham N, Hoffman M and Van der spy ZM Infertility in South Africa: women's reproductive health knowledge and treatment seeking behaviour for involuntary childlessness. Human Reproductive Health. 2002; 17(1): 1657-1662.

23. McCabe KM Factors that predict premature termination among Mexican-American children in outpatient psychotherapy. Journal of Child and Family Studies. 2002; 11 (3): 347-359.

24. Chadwick DD, Jolliffe J and Godbart J Carer knowledge of dysphasia management strategies. International Journal of Language and Communication Disorders. 2002; 37(3): 345-357.

25. Bultman DC and Svarstad BL Effects of physical communication style on client medication beliefs and adherence with antidepressant treatment. Patient Education and Counseling. 2000; 40 (2): 173-185. 